\title{
Tales of Early Childhood Education Teachers in Government Schools in Chipata, Zambia
}

\author{
Daniel L. Mpolomoka ${ }^{1 *}$, Moono, Muvombo ${ }^{2}$, Mutinta N. Matimba ${ }^{3}$, Tuke Chulu ${ }^{4}$, Joseph \\ Mate $^{2}$, Mubita Situmbeko ${ }^{2}$ \\ ${ }^{1}$ Research and Consultancy Unit, Zambian Open University, Zambia \\ ${ }^{2}$ School of Education, Nkrumah University, Lusaka, Zambia \\ ${ }^{3}$ Educationist and Consultant, Lusaka, Zambia \\ ${ }^{4}$ Education Standard Office, Chadiza District, Ministry of Education, Zambia
}

\begin{abstract}
This article houses findings of a study that uncovered the provision of early childhood education (ECE) in government schools with a bias towards learners with special education needs. It focused on challenges faced by teachers in providing educational services to children with special education needs at the early childhood education level in the targeted government schools. The rationale of the study was to solicit trends-in-practice among ECE teachers through their stories, thus partly help other teachers who shall read findings of this study tap into their engagements with ECE learners; and partly nurture children's development in a right way in early years. Qualitative methodology was used because it allowed for in-depth realities faced in 5 schools in Chipata. The study employed a descriptive research method for two years from 2016 to 2017, comprising five primary schools in Chipata District, Zambia, were conveniently sampled for the study. Interviews, focus group discussions, and questionnaires were used to collect data, which was analysed qualitatively. The study revealed challenges that are quite universal for teaching early childhood education learners. Teachers in this study expressed the need for reduced class sizes, adequate learning and teaching materials, teacher extrinsic motivation, additional support services from the government, and an accommodative curriculum. The study further revealed that early childhood education centres in government schools in Zambia at large have poor learning environments specially to support the learners with special education needs. The study showed that collaboration between early childhood education teachers and parents is necessary for the wellbeing of their children. The study recommends that the government should invest in infrastructure development for ECE centres; and that schools should purchase appropriate learning and teaching materials and stock ECE centres.
\end{abstract}

Keywords: Early Childhood, Learner, Schools, Special Education Needs, Teacher.

\section{Introduction}

Early childhood education, commonly referred to as ECE which, is a broad term used to describe the education programs of children in their pre-school years before they are old enough to enter grade one or elementary school. ECE is important because it is a stage that a child acquires basic language and numeric skills while contributing a child's fundamental foundation to cognitive, social, moral, physical spiritual and personality development. In Zambia, for a long time, early childhood education was only offered by private schools despite government training ECE teachers is some teachers training colleges. It was not until 2013 when the government 
decided to establish early childhood education centers across the country mostly in primary schools. This paper will, therefore, discuss challenges early childhood education teachers face in government schools.

Early Childhood Care and Education (ECCE) is defined as "service and programme that support children survival, growth, development, and learning including health, nutrition and hygiene and cognitive social, emotional and physical development from birth to entry into primary school" [1]. From this definition, it can be seen that early childhood education involves a lot of things because it is taken as a full package. It also serves as a preparatory phase for entry into primary school [2-4].

The introduction of early childhood education in Zambia was a good move because it meant that early childhood education was being earmarked to be available for all Zambian children [5-8]. However, only a small percent of the Zambian children population was benefiting from this programme, and these were children mostly from urban areas and from well-to-do families. Good as the move was, teachers of early childhood education in government schools are facing various challenges in their work.

\section{Statement of the Problem}

Most schools mandated to teach early childhood learners need to be furnished with adequate resources among other, recreation facilities, sensory equipment, books, in order to make the centres provide a conducive environment. Despite the emphasis by UNESCO in the Salamanca statement that every child must be provided with quality and relevant education [9], the overall quality of early childhood education in government schools in Zambia remains far below the expected standard $[7,8]$.

Lack of teaching facilities and inappropriate environment have a negative effect on the delivery on quality education provided to preschool learners, especially children with special education needs. In many schools, over- enrollment is eminent against few teachers who are expected to facilitate learning in most ECE centres.

\section{Objectives}

1. To establish approaches and methods used to teach early childhood learners in government schools.

2. To determine the extent to which parents of children in government early childhood education centres collaborate with early childhood teachers.

3. To establish common activities between private early childhood education centres and government schools.

\section{Rationale}

The rationale of the study was to tap into the tales of ECE teachers, thus cultivating the holistic development of a child's social, emotional, cognitive, and physical needs on the one hand, and build an enriched and firm foundation for lifelong learning and wellbeing, on the other.

\section{Materials and Methods}

A convenient sampling procedure was used for the study. This technique was chosen because it allowed for the target and selected ECE teachers in the schools with a bias to those teaching children with special needs. The study used a descriptive research method that took two years, 2016 - 2017 [10]. The selected schools were representative of early childhood learning in the primary school level of education. In addition, the selected schools for the study were representative of the social classes of the community also representative of all the income bracket groupings of the population in which the schools were located.

Ten (10) parents of children with special needs and twenty-five (25) selected teachers from five (5) schools participated in the study. The reason for selecting twenty-five (25) teachers was for the purpose of reducing the degree of bias during data collection. The researchers selected twenty-five (25) teachers 
from five primary schools, of which fifteen (15) were special education teachers while ten (10) were general education teachers.
The school's sample size consisted of five primary schools. These primary schools were Msekera Primary, Mpezeni, Nadalistika, St. Atanazio, and Katopola.

Table 1. School Categories, Schools and Population of Respondents

\begin{tabular}{|l|l|l|l|}
\hline School Category & Name of school & Community Class & School population \\
\hline \multirow{5}{*}{ Primary level } & Msekela Primary & Low-cost area & 1000 pupils \\
\cline { 2 - 4 } & Meena Primary & High-cost area & 1000 pupils \\
\cline { 2 - 4 } & Nadalistika Primary & High-cost area & 500 pupils \\
\cline { 2 - 4 } & St. Atanazio Primary & Low-cost area & 800 pupils \\
\cline { 2 - 4 } & Katopola Primary & Low-cost area & 1000 pupils \\
\hline
\end{tabular}

Unstructured questionnaires were distributed to and completed by respective teachers of special education and general education and, in some cases, senior teachers who were delegated authority by the headteacher. Other participants who responded to questionnaires were class teachers, school zonal coordinators, retired headteachers, and retired teachers. Focus group interviews were also conducted with some of the mentioned study participants.

Data was analysed qualitatively using themes guided by the research objective (thematic analysis). This method of data analysis was chosen because the larger part of the research findings were descriptive responses from the questionnaire and interviews.

\section{Results}

\section{Issues in Early Childhood Education}

The following is a presentation of results providing answers to the three research questions. The research findings were in the form of responses to the questionnaires. The information was drawn from parents and teachers with many years of experience in the education system. In order for early childhood education to be effective, the teacher-pupils ratio must be low and reasonable.

"There are few early childhood education teachers; hence, in a class, there are usually a lot of learners to be handled by one teacher, making it so difficult to focus on individual learners".

\section{Early Childhood Education Teaching and Special Education}

Results when teachers were asked on how they were managing early childhood education teaching. The findings indicated most teachers' inability to manage such classrooms as evident in the caption below.

'Sometimes the lack of specialized skills to handle some disabilities in case of a class with learners of different conditions' makes it difficult to effectively manage classes and children (School Administrators at school A, school C, and school D).

From the results on appropriate or relevant early childhood education training of teachers for learners with special needs, some parents interviewed revealed the following:

"For learners with Visual Impairment, mobility challenge is a common factor even at pre-school level, therefore there is need for personnel who can train these learners with selfmobility skills vital for play activities, both at home and at school."

From the research findings on playgrounds in schools, teachers in government schools said this:

The suitable playgrounds are either not there or not suitable for ECE children especially those with disabilities.

When teachers were asked on whether they had the appropriate infrastructure for ECE in 
centres, one teacher's sentiment was in tandem with other teachers views when she said that:

'There is generally lack of appropriate infrastructure in ECE centres as infrastructure is usually that which is meant for primary age groups.'

Further results on infrastructure showed that most pre-schools lack adequate sanitation, ventilation, clean water and food in order for ECE children to grow and develop physically, emotionally, socially, and mentally and be health. Most teachers said that most infrastructure was just adapted and not built for ECE; toilets for example, were not suitable for such young learners.

Results on prioritizing ECE, one parent further revealed that schools tend to support extra-curricular instead of investing in the programme of early childhood education.

'My child was diagnosed with a condition said to be cerebral palsy, he faces problems to access the toilet such that it's difficult to let child go to school alone without a helper to take him to the toilet especially the ones in primary schools. Schools need to invest in suitable toiles, but they seem to spend more on sports than on making sanitation facilities accommodative to all children', (Female Parent, Aged 47, Business Lady).

When it came to financial issues, it was revealed that most children in Zambia who are in government schools are from families who have financial challenges. And most parents cannot afford to take their children to pre-school, they thus wait until children reach primary school age.

Results indicated that the children's first language and his or her second language had an influence on ECE children, thus providing challenges in learning. Children learn local languages first, and then they are exposed to the learning of English. One teacher commented that:

'Learners with special needs find it difficult to adapt from local languages to English during the learning process. This situation was noted among children at school D' (Male, Special education teacher, aged 46, School $d_{2}$ ).

\section{Early Childhood Teachers and learners with Special Needs}

Teachers who teach children with special needs also face difficulties coming from the socalled 'normal' teachers or traditional teachers. An example of this cited by such teachers reveals the following:

'Teaching learners who are slow may require time, but normal teachers would attach a stigma to it and perceive work of special education teachers who teach learners with disabilities work as less important and because of their lack of understanding about the principle of working with small groups of children with disabilities.

Special education teachers find themselves having to do a lot of work, such as conducting assessment planning for the child's individualized education plan and a lot of other paperwork for each child's file.

'Every child with special education need requires an individualized program but looking at the pupil-teacher ratio, we fail to do all necessary paperwork like evaluating child's individual plan' (Female, Special education teacher, aged 37, School $A_{2}$ ).

\section{Community Support for Early Childhood Education}

The results pertaining homework given to children indicated that very few parents help the learner's homework.

'It takes time to teach, and the activities take more time too; I tried to help her with her homework, but the same homework was given to my child and neighbors; you find_my child can't color maybe only the teacher can manage, otherwise, at home, we have tried and have failed as we have other important tasks to do such as home chores' (Male Parent, Aged 50, a Farmer, whose child is autistic).

When it came to whether salaries had an influence on teaching, teachers in Zambian government schools indicated that the salaries 
are the same for teachers and that this was very unfair because teachers for E.C.E are most stressed and do a lot of work than any other teacher in the primary section. One teacher explained the following:

'In our case as special education teachers at our schools, we are supposed to attend to learners with disabilities sent to us by 'ordinary' teachers. We are supposed to handle such learners with disabilities despite having our own classes that we teach. This gives us more workloads, including planning for all learners plus those that need special attention like the blind and hearing impaired in our inclusive classes' (Teachers aged 34, 27, 24 school $A_{1}$, school $B_{2}$, and school $C_{1}$, respectively).

\section{Transport System - for ECE Learners}

The effective provision of quality early childhood education also faces the challenge of providing transport to the learners or children.

The government did well by establishing early childhood centres across the country, but the technocrats must have consulted wide enough, and there is a need to invest more money in this programme, especially in the transport facilities for ECE children and those with disabilities for this education to be successful (Female, aged 28, School $A_{1}$ ).

\section{Whose Mandate Should it be to Run ECE?}

On whose mandate is it to run ECE, results by teachers indicated that the government should leave early childhood education for private schools in urban areas and invest it in rural areas. It was also revealed that the government should provide financial and human resources to remote and rural early childhood centres.

From the focus group discussions on whose mandate is it in implementing ECE, Teachers explained that the school is also expected to play a key role in implementing early childhood education programmes.

This programme can also be successful if schools reserved a space for early childhood education and invested more in such by building modern infrastructures for early childhood education and provide security and transport (Male, aged 31, School $B_{2}$ ).

This can be a good move, and it can be like having two schools in one school. The challenges can then be alleviated, and early childhood education can be a success (Female, aged 40, School $C_{1}$ ).

\section{Discussion}

The discussion of findings is drawn from the results presented above.

\section{Issues in Early Childhood Education}

The findings on issues in early childhood education established that early childhood education in government schools faces several challenges, one of which is the lack of enough teachers and maids in government schools. Farrant [11] alludes to this when he states that many African schools have a shortage of teachers at all levels of education, the worst being the early childhood department. The Zambian Government has deployed some teachers of early childhood education in the country, but the number is very negligible and could not meet the demands of such teachers in public schools.

\section{Early Childhood Education Teaching and Special Education}

Most teachers interviewed stated that early childhood education is a very sensitive job that needs well-qualified teachers from recognized colleges and universities.

Further posits that a standard early childhood care education class must have two key personnel per setting; a teacher of early childhood education and a maid in attendance to assist the teacher in caring for children during the teaching and learning experiences [12].

A teacher will teach content and facilitate learning and play activities to the children in class while a maid takes care of children`s welfare such as feeding, napping, toileting, general cleanliness, cleaning the class, and 
ensuring the safety of the children. To expect a teacher to deal with all these at the same time would be expecting too much from one person. This is worse for teachers teaching learners with special education as such learners demand more attention and care.

The Zambian government does not train or deploy any maids to schools. The teacher, therefore, does the teaching and the work that the maid is supposed to do. Teachers handling learners with special education needs are often overwhelmed especially when they handle inclusive learners in their classrooms.

From the findings in the focus group dissuasions, it was evident that teachers for early childhood education are finding it a challenge to play with children because there are no suitable playgrounds in most schools housing ECE children. Without appropriate playgrounds, early childhood education can never be effective and a good preparation for entry into primary schools. According to [13], a perfect pre-school needs to have a perfect playground with suitable playing equipment, a conducive environment, and with strict supervision. This is because, at pre-school, there are children who are aged 6 and below who can easily get hurt during play activities. Therefore, the most effective method of teaching and care should be involved or utilised during 'play' [8, 14-17]. This calls for government schools and teachers to ensure that there is a suitable playpark or playground at the school.

A Study contends that children in the kindergarten stage of pre-schools need proper sanitation, ventilation, and clean water food in order to grow and develop physically, emotionally, socially, and mentally and be healthy $[7-8,18]$. This is one of the basic needs in life, and children must have these in place [2, $3,7,8,19]$. In line with the findings, most government schools use latrines which are not suitable for children who are below the age of six because they are old models where a child has to squat. The structures of the schools are poorly ventilated are normally dusty and unclean as they are cleaned sometimes without disinfectants. On financial challenges, [1] states that most children in Africa who are in government schools are from families who have financial challenges. This is true in Zambia because records of children show that these learners are from a background of low socioeconomic status. As a result of this, children under early childhood education are unable to pay for their schools because the parents cannot afford the fees. The money realized from the fees of pre-school learners is not enough to sustain the running of the centres. Funding from the government is also inadequate, making it difficult for teachers to modify their teaching, especially for children with special needs.

From the discussions on education materials, the findings were in line with [20] statement that most children in African countries are not exposed to educational materials until they are about 10 years. This is one of the descriptors of the learners in Zambia. Children in Zambia start schooling at the age of 7 years, and they are not well developed cognitively, are too playful, their intelligence quotient IQ is low, especially those from families of low socio-economic status, lower and middle class. Children in Zambia mostly use the local language (LI) and very little of speaking English as an official language or learnt as a second language (L2).

Due to the challenges in learning the English language, Early childhood education has a lot of tasks as these children need to start from the beginning to learn things around them and be able to use instruments and equipment which seem to be new to them. The learner descriptors stated above need to be changed so that early childhood education is going children can be helped to become good at school activities and improve their livelihood status in future life and be able to speak the offered language, English.

\section{Early Childhood Teachers and Learners with Special Needs}

From the findings in the results, it is evident that dealing with multiple disabilities is one 
challenge teachers of early childhood education face as learners with disabilities exhibit unique disabilities. This calls for them to have a special education program planned yearly specifically modified to meet their learning needs to be called an Individualized Education Programme (IEP). The discipline of learners with special needs in a classroom is one challenge that teachers of early childhood learning face. Some learners may have behavioural issues, attention problems, being moody, to mention a few. This may need the teacher to understand the child and know how to help the child despite the large numbers of learners, especially in inclusive education [21-23].

\section{Community Support for Early Childhood Education}

In relation to community support for early childhood Education, what early childhood education teachers face is that some parents and communities are not helping them or supplementing their work. Some parents do not care about the education and welfare of the children and only leave the work for teachers. This is evident in the attitude of parents who would rather start investing their children's education at the primary level and not at early childhood education hence the low enrolment levels in some schools.

From the findings, most teachers explained that early childhood education is hard work. This is in line with findings by other scholars that the most hardworking teachers in any education system are teachers for early childhood education because their work involves taking care of babies by looking after them at all times, feeding them properly, teaching them, and ensuring that they are safe $[8,11,19,21,23]$.

\section{Motivation for ECE Teachers}

From the discussions, Early childhood teachers complained of meagre salaries. Like any other employee, salaries for early childhood teachers must be motivating enough to enable them to stay in the profession and perform their work well. Poor remuneration of ECE teachers can be seen as a challenge because teachers remain less motivated, and this is the reason why most teachers for early childhood education decide to upgrade so that they teach at other levels of education, namely primary or secondary. Unanimously, teachers also complained about the lack of support from administrators in terms of teaching and learning materials. The negative attitude from parents was another challenge, especially from rural areas, because they do not value the benefits of taking their children early to school. This led to low enrolment levels for children in rural areas.

\section{Transport System - for ECE Learners}

Early childhood education also faces the challenge of providing transport to the learners or children. A standard early childhood education must have, according to [12], a school transportation system where children can be transported from home to school, school to home, and on tours. This is not so in government schools because there are no transportation means such as school buses. Parents are the ones that take learners to schools, and they must pick up children from schools on a daily basis. This is the challenge the teachers face in government schools in trying to market their services as parents in urban areas prefer private ECE schools to government ones. But private schools have systems and have school buses and have employed drivers to pick learners from homes, taking them to schools and back home daily.

In order to improve the provision of ECE in government schools, especially those in rural areas, the Government of Zambia should provide a school bus and employ a driver to pick up children from their home and to take children on educational tours, a bus at least for every government school.

\section{Whose Mandate should it be to Run ECE?}

From the discussions on whose mandate is to provide ECE, teachers questioned the realism of 
government running ECE centres in rural areas. This is because many social-economic amenities do not follow such pronouncements and new establishments. Unanimously, teachers indicated that the government should leave early childhood education for private schools in urban areas and invest it in rural areas. It was also revealed that the government should provide financial and human resources to remote and rural early childhood centres.

\section{Infrastructure for ECE}

In relation to infrastructure, Zambia was found to be one of the countries in Africa were the infrastructure and facilities in government schools are not safe and conducive for early childhood education to be conducted. The infrastructure that accommodates the early child sections are as old as the primary schools when early childhood education started in 2013 [5, 8, 21, 23]. Finding further indicated that each school is also expected to play a key role in investing in ECE and implementing early childhood education programmes. The school can help by rehabilitating some classrooms for early childhood education, procuring relevant books and other learning materials, reserve an area for a suitable playpark. This is, however, hampered by the poor funding of the schools.

\section{Conclusion}

This article has brought out the plight of early childhood teachers in government schools. Amongst the challenges they face are the lack of resources and materials and appropriate infrastructures such as toilets, water points, classrooms, and playparks with relevant equipment. This includes the lack of teachers in some schools and maids, no transport and security, poor sanitation, and ventilation (toilets and bathrooms), poor enrolment in most government schools, and the parents' not paying school fees. Like most research findings in ECE, the findings of the study contend that the general provision of education services at the early childhood educational level needs a multisectoral approach so as to attend to the individual needs of children at the pre-school level if a holistic educational life is to be achieved. For instance, early childhood education for children with special education needs extra attention in terms of curriculum adaptation, teaching methods, assistive technology, assessment systems as well as other resources and funds in adapting to the school environment to suit the needs of ECE learners, especially those with special needs.

\section{Conflict of Interest}

None of the authors of this manuscript has declared any conflict of interest which may arise from being named as authors (on this manuscript).

\section{Acknowledgements}

This paper and the research behind it would not have been possible without the exceptional support of colleagues who have co-authored it. We also extend gratitude to Febby Mbewe and Phydes Nguni, whose invaluable input is highly appreciated. We further appreciate initial comments on the paper made various delegates when it was presented at the $6^{\text {th }}$ International Conference on Education for Sustainable Development (ICESD-2020) held at Kwame Nkrumah University, Kabwe, Zambia June 28 29, 2021. 


\section{References}

[1] United Nations Education, Scientific and Cultural Organization (UNESCO) (2010). The World Conference in Early Childhood Care and Education Building the Health of Nations. Paris: UNESCO.

[2] Tuntufye, S.M. (2014). Early Childhood Education in Africa. Mediterranean Journal of Science, Roma: MCSER publishing.

[3] Richter, L.M., Daelmans, B., Lombardi, J., Heymann, J., Boo, F. L., Behrman, J. R., Dua, T. (2016). Investing in the foundation of sustainable development: Pathways to scale up for early childhood development. The lancet.

[4] Mwanza-Kabaghe, S. (2015). Preschool, Executive functions, and Oral Language as Predictors of Literacy and Numeracy skills in First Grade. Ph.D. Thesis: Unpublished. University of Zambia.

[5] Mulunda, T.M. (2017). Provision of early childhood education to children with special educational needs in selected inclusive primary schools of Kabwe District, Zambia. Master of Education in Special Education dissertation, University of Zambia (Unpublished).

[6] MESVTEE (2013). Early Childhood Education National Policy (draft). Lusaka: MESVTEE.

[7] Matafwali, B. and Zingel, M. (2017). Early childhood development program for children affected by HIV and AIDS in rural Zambia. A report on the Program of Episcopal Relief \& Development and Zambia Anglican Council Outreach Programmes (ZACOP).

[8] Matafwali, B. and Munsaka, E. (2011). An evaluation of community-based early childhood Programmes in Zambia: A case of four selected districts. Journal of Early Childhood Development, 5 , 109-131.

[9] UNESCO (1994). The Salamanca Statement and Framework for Action on Special Needs Education. Paris: UNESCO.

[10] Banda, S., Mpolomoka, D.L., Mbono, D. and Sampa, R.L. (2017). Use of questions in qualitative research: How questions guided our study, International Journal of Development Research, 7, (12).

[11] Farrant, J.S. (1980). Principles and practices of education. London: Longman.
[12]Clark, R.M. (2015). Childhood Education in society ( $2^{\text {nd }}$ Edition). London: Learning matters cetre. [13] Wesley, W.P. and Buysee, V. (2005). Consultation in Early Childhood Settings. Baltimore: PH Brookes.

[14]Lungu, S. and Matafwali, B. (2020). Play based learning in early childhood education (ECE) centres in Zambia: A teacher perspective. European Journal of Education Studies, 7(12), 356-369.

[15] UNESCO (2016). Education for people and planet: Creating sustainable futures for all, Global Education Monitoring Report. UNESCO: Paris.

[16] UNICEF (2018). Learning through play: Strengthening learning through play in early childhood education programmes. New York: UNICEF.

[17] United Nations Children's Fund (2019). A World Ready to Learn: Prioritizing quality early childhood education. New York: UNICEF.

[18] Chikopela, R., Chitundu, D. and Mpolomoka, D.L. (2020). Perceptions on Teachers in Commuter Marriages. Chalimbana University Multidisciplinary Journal of Research, 1(2)80-87.

[19] Mabenga, M.M. and Mpolomoka, D.L. (2017). Critical factors in early childhood education: policy and practice. Palgo Journal of Education Research, 5(4), 292-297.

[20] United Nations Educational, Scientific and Cultural Organization UNESCO (2006). Education for all. Global Monitoring Report Strong Foundation. Early childhood Care and Education. Paris: UNESCO.

[21]Zuilkowski, S. S., Fink, G., Moucheraud, C. and Matafwali, B. (2012). Early childhood education, child development and school readiness: Evidence from Zambia. South African Journal of Childhood Education, 2(2), 20.

[22]Fink, G., Matafwali, B., Moucheraud, C., Simmons-Zuilkowski, S. (2012). The Zambian Early Childhood Development Project: Round I Final Report. Cambridge: Harvard Center on the Developing Child.

[23] Fink, G., Zuilkowski. S.S, Matafwali, B. (2011). The Zambian Early Childhood Development Project: Round I Final Report. Cambridge, MA: Harvard Center on the Developing Child.

[24] Steven, B.S. (2001). Teaching Children in Elementary Courses and Schools. London: Longman. 